\title{
Besoyong Dalam Pesta Adat Belian Paser Nondoi di Kabupaten Penajam Paser Utara Kalimantan Timur
}

\author{
Retno Kristanti ${ }^{1}$
}

\begin{abstract}
Besoyong is derived from the word soyong which means the spell or prayers, then besoyong means speaking or singing the spell. Besoyong is usually used by Paser tribe as the media to speak to the ancients spirits and Sangiyang through their daily lives. Besoyong has started to be sung in Traditional Festival of Belian Paser Nondoi once a year at Penajam Paser Utara regency, East Kalimantan. This research explains about presentations form of besoyong continue with internal and external incentive factors of besoyong presence in Traditional Festival of Belian Paser Nondoi. This research uses the theory of Alvin Boskoff about internal and external's factors of social change applied as internal and external incentive factors of besoyong presence in Traditional Festival Belian Paser Nondoi. Besoyong can be presented individually and also with ensemble. Internal incentive factors of besoyong presence are to elude from evil ghosts, as the mean to invoke clear weather for the festival, as the mean of healing and ast the mean of asking blessing. External incentive factors of besoyong presence are to elevate the district economics \& tourism, and to be functioned as the identity of this region.
\end{abstract}

Keywords : Besoyong, Traditional Festival of Belian Paser Nondoi, community

\begin{abstract}
Abstrak
Besoyong berasal dari kata soyong yang berarti mantra atau doa, maka besoyong berarti berbicara atau menyanyikan mantera. Besoyong biasanya digunakan oleh suku Paser sebagai media untuk berbicara kepada roh-roh dahulu dan Sangiyang melalui kehidupan sehari-hari mereka. Besoyong telah mulai dinyanyikan dalam Festival Tradisional Belian Paser Nondoi setahun sekali di Kabupaten Penajam Paser Utara, Kalimantan Timur. Penelitian ini menjelaskan tentang bentuk presentasi besoyong yang dilanjutkan dengan faktor insentif internal dan eksternal dari kehadiran besoyong di Festival Tradisional Belian Paser Nondoi. Penelitian ini menggunakan teori Alvin Boskoff tentang faktor internal dan eksternal dari perubahan sosial yang diterapkan sebagai faktor insentif internal dan eksternal dari kehadiran besoyong di Festival Tradisional Belian Paser Nondoi. Besoyong dapat disajikan secara individual dan juga dengan ensemble. Faktor insentif internal dari kehadiran besoyong adalah untuk menghindari dari hantu jahat, sebagai maksud untuk memanggil cuaca yang jelas untuk festival, sebagai sarana penyembuhan dan ast berarti meminta berkah. Faktor insentif eksternal dari kehadiran besoyong adalah untuk meningkatkan ekonomi distrik \& pariwisata, dan berfungsi sebagai identitas daerah ini.
\end{abstract}

Kata kunci: Besoyong, Festival Tradisional Belian Paser Nondoi, masyarakat

\footnotetext{
${ }^{1}$ Mahasiswa jurusan Etnomusikologi FSP ISI Yogyakarta.
} 


\section{Pendahuluan}

Besoyong, nyanyian mantra yang berasal dari suku Paser telah mulai dilantunkan beberapa tahun terakhir melalui Pesta Adat Belian Paser Nondoi di Kabupaten Penajam Paser Utara. Menurut asal katanya, besoyong berawal dari kata soyong yang artinya mantra, sehingga orang yang sedang mengucapkan atau melantunkan mantra disebut sedang besoyong dalam bahasa Paser. Besoyong biasa dilakukan oleh dukun atau mulung dalam upacara belian maupun ritual adat suku Paser lainnya, namun tidak semua orang dapat melantunkan mantra tersebut dengan fasih dan indah didengar. Mereka yang melakukannya ialah orang yang terbiasa menjadi pemimpin upacara atau ritual adat (seperti mulung) ataupun orang yang dipilih untuk menjadi mulung atau mantan mulung (tidak memimpin ritual adat lagi).

Suku Paser telah lama bermata pencaharian dalam bertani. Pembukaan lahan biasanya memiliki ritual dengan berbicara kepada penghuni atau pemelihara hutan untuk meminta izin bila diperbolehkan membuka lahan tersebut atau tidak melalui besoyong oleh dukun atau mulung (Yusuf, 2004 : 12). Besoyong juga merupakan nyanyian mantra yang panjang dan dilakukan saat ritual atau upacara belian sehari atau dua hari bahkan satu minggu yang dilaksanakan khusus oleh keluarga suku Paser namun terkesan lebih tertutup. Isi nyanyian mantra umumnya dipercaya untuk menyampaikan maksud dan tujuan atau niat hajat dari warga kepada roh-roh leluhur seperti memohon keselamatan dan perlindungan dari tempat tinggal mereka di Kabupaten Penajam Paser Utara.

Kabupaten Penajam Paser Utara merupakan hasil perkembangan wilayah dari Kabupaten Pasir yang letaknya mendekati daerah paling selatan dari Provinsi Kalimantan Timur. Kabupaten Penajam Paser Utara dan Kabupaten Paser (perubahan sekarang), dua kabupaten tersebutlah yang memiliki penduduk dinamakan Suku Paser.

Suku Paser sebelum mengenal adanya agama, merupakan penganut kepercayaan nenek moyang kuno seperti animisme, syamanisme dan ilmu - ilmu gaib. Besoyong atau nyanyian mantra dapat diperkirakan sudah lama dilakukan sejak sebelum Kerajaan Sadurengas (Kerajaan pertama di Paser) terbentuk. Agama Islam mulai masuk berawal perkawinan dari Raja Paser, Putri Petong (1516 -1567 M) dengan Abu Mansyur Indra Jaya dan adanya jalur perdagangan Sungai Kandilo yang mempertemukan warga dengan pedagang Arab (Yusuf, 2004:26). 
Masyarakat suku Paser mulai memeluk agama Islam dan hampir seluruh tatanan masyarakat juga menyesuaikan dengan syariat Islam sampai saat ini, walaupun begitu agama Kristen dan yang lainnya juga sudah masuk dan dianut sebagian dari warga suku Paser. Masyarakat suku Paser juga terbuka dan toleran bahkan dalam kesenian budaya dan adat yang ada. Keyakinan yang dianut tidak menghalangi masyarakat untuk tetap melaksanakan ritual atau upacara adat yang diwariskan oleh nenek moyang. Masyarakat Paser yang hidup berkumpul dalam satu wilayah masih menyanyikan mantra atau besoyong dalam kegiatan bersama sehari - hari dan saat ini dilakukan dalam Pesta Adat Belian Paser Nondoi.

Mulai tahun 2014 lalu, suku Paser melalui Lembaga Adat Paser dan Lembaga Swadaya Masyarakat di Kabupaten Penajam Paser Utara dan beberapa kabupaten sekitar mengumpulkan niat mengadakan event masyarakat yang mengangkat belian nondoi. Pesta Adat Belian Paser Nondoi di Kabupaten Penajam Paser Utara sendiri menjadi salah satu ikon untuk mempersatukan masyarakat dalam mengenal suku Paser. Pesta Adat yang sama mulai diadakan kembali pada 18 oktober 2017 hingga 26 Oktober 2017 setelah tahun 2014, 2015 dan 2016 juga telah dilaksanakan acara serupa.

Pelaksanaan Pesta Adat tersebut telah dilindungi Pemerintah dalam Peraturan Daerah Kabupaten Penajam Paser Utara No 2 tahun 2017. Peraturan Daerah berisi mengenai Pelestarian dan Perlindungan Adat Paser yang khususnya tercantum dalam Bab II pasal 4 ayat $2 \mathrm{~d}$ yang berbunyi "penyelenggaraan kegiatan tahunan adat paser Nondoi”. Keinginan masyarakat suku Paser di Kabupaten Penajam Paser Utara untuk mengangkat kebudayaan Paser bagi khalayak umum terwujud. Suku Paser menikmati keindahan budayanya dan suku-suku pendatang juga dapat menyaksikan segala aspek dari suku Paser melalui Pesta Adat ini.

Aneka makanan dan minuman hingga pakaian dan buah-buahan berjejeran disalah satu tepi jalan masuk menuju Lapangan Pasar Induk Penajam Km 04, Kelurahan Nenang, Kabupaten Penajam Paser Utara, Kalimantan Timur. Panggung hiburan, display pameran oleh-oleh tradisi Kalimantan dan kuta (rumah/ tempat ritual adat berlangsung) khusus menempati lapangan besar yang disediakan. Kesenian disajikan melalui panggung hiburan, mulai dari tari-tarian daerah, seniman gambus, lomba betore /pantun daerah, bekuntau/ seni bela diri Paser, dan lainnya. Saat malam hari baru diadakan ritual adat belian nondoi, besoyong dan ansambel musik petep yang dimulai 
pukul 9 malam hingga subuh. Ritual adat Paser diadakan terbuka namun prosesnya tetap sarat dengan suasana sakral. Besoyong awalnya hanya disajikan di tempat-tempat tertutup, kali ini dapat dikenal oleh masyarakat luas melalui Pesta Adat Belian Paser Nondoi di Kabupaten Penajam Paser Utara. Kehadiran ansambel musik petep dan nyanyian soyong dilantunkan setiap malam atau ketika belian itu berlangsung hingga menuju hari penutupan acara.

Penulis melakukan penelitian berbasis model metode etnografi yang merupakan salah satu penelitian kualitatif yang berisi deskripsi kehidupan masyarakat dalam beragam situasinya dan sebagaimana adanya, seperti yang terlihat dalam kehidupan kesehariannya, cara masyarakat memandang kehidupan, perilaku dan semacamnya (Muhadjir,1989: 168). Adapun menurut Noeng Muhadjir menggolongkan metode etnografi dalam model paradigma naturalistik yang menempatkan manusia sebagai instrumen utama penelitian. Faktanya, naturalistik cenderung menyusun teori pada waktu di lapangan sedangkan model paradigma lainnya seperti positivistik dan rasionalistik menyusun teori dari konseptualisasi sebelum terjun kelapangan.

Pembahasan mengenai alasan bahwa soyong atau mantra dihadirkan dalam Pesta Adat Belian Paser Nondoi akan dianalisis menggunakan teori Alvin Boskoff mengenai faktor eksternal dan internal dari perubahan yang terjadi, namun dalam hal ini diaplikasikan menjadi faktor eksternal dan internal pendorong kehadiran besoyong dalam Pesta Adat Belian Paser Nondoi (Boskoff, 1964:141). Faktor eksternal berasal dari kontak antar budaya yang dalam hal ini terdapat kontak antar pengunjung atau wisatawan dan Pemerintah Daerah Kabupaten Penajam Paser itu sendiri. Faktor internal ialah yang berasal dari pemilik kebudayaan itu sendiri yakni suku Paser dan pelaku yang ada didalam Pesta Adat Belian Paser Nondoi, terutama mulung sebagai pelantun mantra atau soyong.

\section{Besoyong Dalam Pesta Adat Belian Paser Nondoi}

Musik adalah salah satu cabang dari kesenian, dimana kesenian itu merupakan ekspresi dari kebudayaan itu sendiri (Takari, 2005 : 22). Besoyong yang dilakukan oleh mulung memungkinkan kelancaran selama Pesta Adat Belian Paser Nondoi berlangsung dengan kata-kata permohonan yang ditujukan kepada roh-roh gaib seperti tidak boleh hujan dan supaya tempat yang digunakan aman dari kejahatan. 
Pesta Adat Belian Paser Nondoi menyediakan panggung hiburan, bazar makanan dan minuman, buah-buahan, stand-stand souvenir dan tentunya belian nondoi. Besoyong hadir didalamnya dengan tujuan yang utuh untuk pelaksanaan belian nondoi. Belian nondoi tidak dapat dilaksanakan tanpa kehadiran besoyong yang dilakukan oleh mulung. Bila hanya terdapat instrumen ansambel tung petep sekalipun, besoyong merupakan hal yang utama untuk menyampaikan maksud dan tujuan kepada Sang Penguasa/Sangiyang. Besoyong berisi doa-doa yang panjang dengan bahasa suku Paser yang tidak dapat dimengerti oleh orang awam begitu saja. Berikut adalah salah satu bait soyong yang dilantunkan mulung saat melakukan tahap ritual belian nondoi dalam Pesta Adat Belian Paser Nondoi :

Upak nang posit daya nang rumbed isau nang kuman kayan pea nang pakai tangis

Tuo nang kendulu rendong utok, beleleng nang ngalung wae Jala uran nang bewet, ilat nang ngaro pendat nayu nang mamorbe

Kalimat diatas adalah soyong yang berisi permohonan untuk menjaga siapa saja termasuk masyarakat yang datang dan hadir dalam belian nondoi di Pesta Adat Belian Paser Nondoi agar tidak terkena bencana atau gangguan yang disebabkan oleh makhluk gaib yang hadir saat ritual dilaksanakan.

Besoyong dalam penerapannya oleh mulung dilakukan juga dengan hati-hati sehingga maksud-maksud pelaksanaan belian tersampaikan kepada makhluk-makhluk gaib dan tidak menimbulkan hal yang merugikan siapapun yang datang. Bait-bait yang dikatakan mulung lewat lantunan soyong dipercaya mempengaruhi apa yang akan terjadi saat itu juga.

Walaupun Pesta Adat Belian Paser Nondoi ini juga dirancang untuk menarik wisatawan tetapi pelaksanaannya tetap tidak meninggalkan ciri-ciri ritualnya seperti memiliki tahap ritual yang sama seperti bila dilakukan dalam masyarakat suku Paser atau tidak berubah; waktu yang digunakan tidak singkat namun sangat panjang dan lama; hampir tidak ada variasi; disajikan dengan cara yang cenderung monoton atau tidak menarik dan memiliki anggaran yang cukup besar ; yang terakhir tidak mudah dimengerti oleh wisatawan atau orang awam yang datang (Soedarsono, 1999:180). Contohnya ketika salah satu pengawal pingsan tidak sadarkan diri saat berada dibelakang sekretaris daerah yang sedang menyampaikan pidato pembukaan pada hari pertama, setelah itu ia dibawa kepada mulung untuk dimantrai dan dipercik dengan daun 
yang diolesi tipong tawar. Merupakan momen yang mengejutkan pagi para hadirin tamu undangan dan masyarakat sendiri, tetapi lewat besoyong oleh mulung hal itu dapat dihentikan. Hal-hal demikian tidak mudah dicerna oleh akal logika manusia namun terjadi. Para pengunjung juga akan menghormati dan tidak sembarangan bersikap saat Pesta Adat Belian Paser Nondoi itu berlangsung.

\section{Faktor Internal}

Faktor internal pendorong hadirnya besoyong dalam Pesta Adat Belian

Paser Nondoi adalah berasal dari orang-orang yang terlibat langsung didalamnya yang memiliki maksud - maksud untuk disampaikan kepada roh - roh leluhur dan Sangiyang, kemudian rangkaian belian nondoi itu sendiri. Orang - orang yang terlibat didalamnya ialah seperti mulung, penggading, orang yang ingin diobati atau ditolong dan suku Paser. Faktor internal yang menyebabkan besoyong hadir dalam Pesta Adat itu adalah sebagai berikut :

a. Menghindarkan dari Roh - roh Jahat

Besoyong hadir didalam Pesta Adat Belian Paser Nondoi faktanya memiliki andil dalam memelihara keamanan yang terjadi selama belian nondoi berlangsung. Maksud memelihara keamanan ini ialah orang - orang yang hadir selama acara berlangsung dapat dihindarkan dari gangguan roh-roh jahat yang datang saat ritual dilaksanakan. Tanpa besoyong maksud-maksud mengamankan demi kelancaran pengunjung yang datang tidak mungkin tersampaikan. Bila terjadi kesurupan karena roh-roh halus yang tidak perlu bahkan dialami banyak orang, maka orang pasti menjadi takut untuk datang dan menganggap bahwa pesta Adat ini tidak dapat dihadiri karena menyebabkan orang kesurupan.

b. Media Memohon Cuaca agar Tidak Hujan selama Acara

Pesta Adat yang diadakan lebih dari sehari ini pasti membuat banyak orang khawatir tentang cuaca apabila terjadi hujan deras maka akan menyurutkan kondisi tubuh orang-orang yang terlibat dalam melakukan ritual belian nondoi maupun keadaan tempat dimana Pesta Adat dilaksanakan. Besoyong juga menjadi media dalam menyampaikan maksud kepada Sangiyang untuk tidak menurunkan hujan selama acara berlangsung.

c. Media Pengobatan

Besoyong melantunkan mantra - mantra yang khusus digunakan untuk 
mengobati orang yang sakit dan meminta pertolongan untuk sembuh. Selama Pesta Adat Belian Paser Nondoi berlangsung, ada orang-orang yang datang untuk meminta agar penyakitnya disembuhkan dan menerima ritual kesembuhan ditubuhnya. Hal ini tentu menarik perhatian penduduk lokal maupun pengunjung untuk datang dan menerima pengobatan dengan cara herbal karena menggunakan minyak khusus yang telah dimantrai atau disoyongi.

d. Media Cari Berkah

Melalui besoyong, maksud-maksud kebaikan dan mulia dimohonkan kepada Sang Penguasa untuk kesejahteraan penduduk daerah dan para pemimpin daerah yang ada. Membersihkan wilayah kabupaten Penajam Paser Utara dari hal- hal yang mencelakakan atau mendatangkan bencana dan memohonkan untuk kesejahteraan mata pencaharian penduduk kepada Sangiyang Nalau, Tondoi dan Longai. Besoyong menyampaikan maksud - maksud tersebut untuk kepentingan bersama.

\section{Faktor Eksternal}

Faktor eksternal pendorong hadirnya besoyong dalam Pesta Adat Belian Paser Nondoi adalah sebagai berikut:

a. Ekonomi Daerah dan Wisatawan

Melalui besoyong dan kelancaran yang dihasilkan maka Pesta Adat akan dapat terus dilaksanakan tanpa ragu oleh Pemerintah Daerah setiap tahun seperti Peraturan Daerah Kabupaten PPU no. II tahun 2017 yang telah dikeluarkan. Pengunjung yang datang maupun penduduk lokal hingga antar daerah hingga turis luar negeri tentu akan menambah pendapatan khusus daerah. Pesta Adat yang diilaksanakan tidak hanya sekedar hiburan namun tetap tidak meninggalkan warisan nenek moyang yang ada, salah satunya ialah nyanyian soyong.

Pengunjung atau wisatawan juga akan mulai banyak tertarik untuk mengenal seni dan budaya yang ada di kabupaten Penajam Paser Utara. Publikasi sederhana dari para wisatawan melalui media sosial tentu mempengaruhi tingkat pengenalan khalayak terhadap tempat - tempat wisata yang menarik di Kabupaten Penajam Paser Utara. Melalui Pesta Adat dengan warisan nenek moyang yang teguh dapat menarik banyak wisatawan untuk berkunjung.

b. Identitas Daerah 
Hal yang ditampilkan melalui kesenian yang ada dan belian nondoi itu yang didalamnya terdapat besoyong mencerminkan suku Paser di kabupaten Penajam Paser Utara. Kehadiran besoyong yang sarat dengan ritual dan memakai bahasa Paser ini mencerminkan suku Paser dalam benak siapapun yang datang dalam Pesta Adat Belian Paser Nondoi. Bentuk penyajian dapat dibagi dua bagian yaitu besoyong secara mandiri dan ansambel tung petep bersama besoyong:

1. Secara Mandiri

Besoyong dapat dilantunkan secara mandiri atau tidak bersama dengan ansambel petep yang terdiri dari lumba, penengkah, tung, gendeng dan kelentangen. Adapun salah satu bagian itu terletak saat 6 tahapan ritual awal selesai yakni sebelum ritual Ngingke Jawaliau yang khusus dinamakan besoyong atau sedang bermantra. Berikut adalah salah satu bait yang dilantunkan :

Intro: $\quad 3 \quad 1 \quad 32 \quad 1$

$\begin{array}{ccccc}3 & .5 & 55 & 32 & 1 \\ P e & \text { ru } & \text { rukngu } & \text { lo le } & o \\ .5 & 55 & 65 & 33 & 3 \\ \text { pa } & \text { yosi } & \text { pen a } & \text { nambu } & \text { ran } \\ .3 & 33 & 33 & 22 & 1 \\ \text { la } & \text { ngit po } & \text { tune } & \text { laom } & \text { bo } \\ .1 & 22 & 33 & 22 & 1 \\ \text { ta } & \text { nawing } & \text { kange } & \text { lai } & \text { wa } \\ .1 & \text { 22 } & 33 & 22 & 1 \\ a & \text { jin bi } & \text { as pa } & \text { lai la } & \text { lo }\end{array}$

Tangga nada yang dipakai :

$\begin{array}{lllccc}\text { Do } & \text { Re } & \text { Mi } & \text { Sol } & \text { La } & \text { Do } \\ 1 & 2 & 3 & 5 & 6 & \text { i }\end{array}$




\section{Secara Ansambel}

Adapun penyajian ansambel tung petep dalam Pesta Adat Belian Paser Nondoi yang dimainkan tanpa besoyong atau mantra dari mulung dan beberapa bagian besoyong yang dilantunkan menurut kebutuhan mulung bersama tung petep.

a. Instrumen yang digunakan

Instrumen menurut sumber bunyinya dapan diklasifikasi menjadi lima golongan yaitu idiophones, aerophones, membranophones, Chordophones (Hastanto \& Hendarto, 2011 : 4). Idiophones adalah instrumen dengan bahan sumber bunyi padat semacam kayu, logam. Aerophones adalah instrumen bunyi yang berasal dari pergeseran udara. Membranophones adalah instrumen dengan bahan sumber bunyi yang terbuat dari selaput. Chodhophones adalah instrumen yang sumber bunyinya berasal dari kawat, senar atau serat dan tali. Berdasarkan penggolongan tersebut, instrumen musik yang digunakan dalan Belian Nondoi ini dapat diklasifikasikan menjadi Idiophones dan Membranophones karena sumber bunyi nya ada yang berasal dari bahan logam dan ada yang berasal dari selaput membran :

1) Idiophones

a). Kelentangen

Alat musik kelentangen ini terdiri dari 6 buah pencu yang terbuat dari campuran kuningan dengan tembaga. Wadah untuk kelentangen sendiri memiliki panjang $\pm 145-$ $150 \mathrm{~cm}$ dan didalamnya dipasang tali-tali untuk memisahkan setiap pencon yang ada. Setiap pencon memiliki diameter $\pm 18-21 \mathrm{~cm}$ dan alat untuk membunyikannya yakni memukul kelentangen dengan kayu lutung yang berdiameter 2- $5 \mathrm{~cm}$ dan panjang antara 16 - $18 \mathrm{~cm}$. Kelentangen ini dulunya dipercaya dibuat oleh para leluhur, namun sekarang masyarakat dapat memesan pembuatannya dari pulau Jawa.

\section{2) Membranophones}

a). Tino

Alat musik tino adalah instrumen dengan dua membran disisi lingkaran yang terbuat dari kulit kijang dan ditempel pada kayu oleh rotan. Panjang tino adalah antara 
$67-71 \mathrm{~cm}$ dengan diameter membran antara $31-33 \mathrm{~cm}$. Tino termasuk dalam ansambel petep yang dibunyikan bersama instrumen kelentangen, lumba, penengkah, tung dan gendeng dengan motif tempo tertentu. Pemain tino hanya 1 orang, dan biasa dilakukan oleh orang yang juga telah terbiasa dengan memainkan ansambel petep di upacara-upacara suku Paser.

\section{b). Penengkah}

Penengkah terbuat dari kayu berbentuk bundar yang kira-kira berdiameter $30 \mathrm{~cm}$ dengan ketebalan kayu atau panjang kayu 15 - $20 \mathrm{~cm}$ dan diberi membran berupa kulit pada salah satu sisi bundarnya.

c). Lumba

Lumba juga instrumen bermembran 1 yang mirip dengan penengkah, namun ukuran diameter membrannya lebih pendek dari penengkah.

d). Tung

Instrumen tung ini memiliki bahan yang sama dengan penengkah dan lumba, namun panjang kayu melebihi kedua instrumen tersebut dan memiliki diameter membran sekitar 10 - $13 \mathrm{~cm}$ yakni lebih pendek dari penengkah dan lumba.

e). Gendeng

Instrumen gendeng ini juga memiliki bahan yang mirip dengan penengkah, lumba dan tung, namun memiliki panjang kayu lebih pendek dari ketiga instrumen tersebut. Gendeng ini didapati berjumlah 2 buah yang digunakan dalam upacara belian nondoi.

b. Pola Tabuhan Instrumen

Kelentangen :

\begin{tabular}{lllll|lllll}
$\mathrm{Kn}$ & $\|: 44$ & 44 & .4 & .4 & 44 & .4 &. & .4 & $: \|$ \\
$\mathrm{Kr}$ & $\|: 33$ & 33 & 2 & .2 & 33 & 3 & 12 & 12 & $: \|$ \\
$\mathrm{Kn}$ & 44 & 44 & .4 & .4 & 55 & .5 &. & 4.5 \\
$\mathrm{Kr}$ & 33 & 33 & 2 & .2 & .2 & 33 & 44.3 & 4.
\end{tabular}


Tung, Lumba, Penengkah dan Gendeng :

$\begin{array}{llllllll}\|: \mathrm{tt} & \mathrm{t} & \mathrm{t} & \mathrm{tt} & \mathrm{t} & \mathrm{t} & \mathrm{tt} & \mathrm{tt}: \| \\ \text { Tino: } & & & & & & \end{array}$

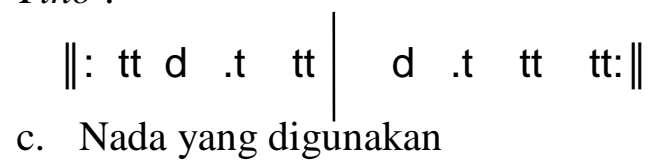

Tangga nada dari instrumen kelentangen juga termasuk dalam hemitonic pentatonic karena banyak memiliki jarak nada yang setengah. Berikut adalah tangga nada kelentangen yang penulis temukan dari buah pencu kiri ke kanan:

$\begin{array}{cllllc}\text { F\# } & \text { G\# } & \text { B } & \text { D } & \text { G } & \text { G\# } \\ 1 & 2 & 3 & 4 & 5 & 6\end{array}$

\section{Kesimpulan}

Besoyong menjadi menarik karena satu-satunya mantra yang diucapkan oleh mulung dalam Pesta Adat Belian Paser Nondoi pada bulan Oktober 2017 lalu. Besoyong dapat dilakukan secara mandiri dalam upacara belian nondoi, namun ada waktu bersama dengan ansambel tung petep.

Besoyong juga menggunakan bahasa Paser yang mengidentifikasikan kekhasan asal suku Paser. Mantra dilantunkan untuk mencegah penduduk dan wisatawan yang ada agar tidak diganggu oleh makhluk-makhluk halus selama Pesta Adat Belian Paser Nondoi berlangsung. Besoyong juga merupakan media yang dilakukan mulung agar tempat selama diadakan Pesta Adat Belian Paser Nondoi tidak diganggu oleh hujan dan gangguan alam lainnya. Besoyong melantunkan mantra - mantra khusus sehingga dapat dilakukan ritual pengobatan bagi pengunjung atau keluarga yang sedang sakit. Ritual belian melalui besoyong juga membantu permohonan kesejahteraan dan berkah bagi daerah tempat tinggal dan pemimpin daerah. Besoyong akhirnya memungkinkan terpeliharanya hubungan antara pengunjung, masyarakat setempat atau penduduk selama Pesta Adat Belian Paser Nondoi berlangsung. Pengunjung dapat menantikan akan Pesta Adat dilaksanakan kembali karena lancarnya acara tanpa gangguangangguan dari makhluk halus dan lain sebagainya. Hal yang menguntungkan daerah sebagai sarana kearifan lokal, pertemuan komunitas, dan masyarakat sebagai pemilik warisan kebudayaan atau pemilik identitas daerah. Maka dalam pada itu besoyonglah yang memungkinkan terjadinya wisata kebudayaan, rasa kepemilikan penduduk akan 
warisan kebudayaan dan menambah pintu gerbang pasar wisata di Indonesia khususnya Provinsi Kalimantan Timur.

\section{Daftar Pustaka}

Boskoff, Alvin.1964. Recent Theories of Social Change. London : The Free Press of Glencoe.

Haryanto.2016. Musik Suku Dayak : Sebuah Catatan Perjalanan. Yogyakarta: Badan Penerbit ISI Yogyakarta.

Hendarto, Sri \& Sri Hastanto. 2011. Organologi dan Akustika I \& II. Bandung :

CV. Lubuk Agung.

Irawati, Eli. 2013. Eksistensi Tingkilan Kutai Suatu Perspektif Etnomusikologis. Yogyakarta: Kaukaba Dipantara.

Mack, Dieter. 1995. Ilmu Melodi di Tinjau dari Segi Budaya Barat. Yogyakarta: Pusat Musik Liturgi.

Muhadjir,Noeng.1989. Metodologi Penelitian Kualitatif . Yogyakarta : Rake Sarasin.

Nakagawa, Shin. 2000. Musik dan Kosmos : Sebuah Pengantar Etnomusikologi. Jakarta :Yayasan Obor Indonesia.

Nettl, Bruno. 1964. Theory and Method in Ethnomusicology. New York : The Free Press of Glencoe.

Prier SJ, Karl Edmund.1996. Ilmu Bentuk Musik. Yogyakarta : Pusat Musik Liturgi.

Retnoningsih, Suharso dan Ana. 2014. Kamus Besar Bahasa Indonesia : Edisi Lux. Semarang: Penerbit Widya Karya.

Riwut,Tjilik. 2007. Kalimantan Membangun Alam dan Kebudayaan. Yogyakarta : NR Publishing

Senen, I Wayan. 2015. Bunyi-bunyian Dalam Upacara Keagamaan Hindu Di Bali. Yogyakarta: Institut Seni Indonesia Yogyakarta.

Soedarsono,R.M.1999. Seni Pertunjukkan dan Pariwisata : Rangkuman Esai tentang Seni Pertunjukkan Indonesia dan Pariwisata.Yogyakarta: Badan Penerbit ISI Yogyakarta.

Soedarsono, R.M. 2001. Metode Seni Pertunjukkan dan Seni Rupa. Bandung : Masyarakat Seni Pertunjukan Indonesia.

Sugiyono. 2009. Metode Penelitian Kuantitatif, Kualitatif dan $R \&$ D. Bandung : 
Alfabeta

Takari, Muhammad. 2005. Studi Banding Antara Tangga Nada Pentatonik dan Diatonik. dalam jurnal Etnomusikologi. No.1.

Takari, Muhammad, Frida Deliana, Fadlin, Torang Naiborhu, Arifni Netriroza, dan Heristina Dewi, 2008. Masyarakat Kesenian di Indonesia. Medan : Studia Kultura.

Wijaadi, Agoes Sri.1996. Upaya Pencaharian Komperatif Bentuk Ungkapan Musikal dalam Kasus Etnomusikologi, dalam Jurnal Pengetahuan dan Penciptaan Seni. Yogyakarta: BP ISI Yogyakarta.

Yusuf,H.M.2004. Adat dan Budaya Paser. Samarinda : Biro Humas Pemerintah Provinsi Kalimantan Timur.

Yusuf, H.M..2012. Asal Suku Paser. Paser : Perpustakaan Daerah Kabupaten Paser.

Zulkarnain, Dt. Iskandar. 2012. Taka Tana Paser : Dalam Perspektif Budaya \& Tradisi. Jakarta : Pustaka Spirit. 